Ettore e Maia (2018)

Análise do Desempenho Contábil-Financeiro das

Empresas Familiares e Não Familiares

\title{
ANÁLISE DO DESEMPENHO CONTÁBIL-FINANCEIRO DAS EMPRESAS FAMILIARES E NÃO FAMILIARES
}

\section{ANALYSIS OF THE ACCOUNTING AND FINANCIAL PERFORMANCE OF FAMILIAR AND NON-FAMILIAR COMPANIES}

\section{ANÁLISIS DEL RENDIMIENTO CONTABLE-FINANCIERO DE LAS EMPRESAS FAMILIARES Y NO FAMILIARES}

\author{
Luís Antônio Gióia Ettore \\ Doutorando, por Doutorado Direto, em Contabilidade e Controladoria com ênfase em \\ Finanças pela Universidade de São Paulo (FEA/USP) \\ E-mail: luisettore@usp.br \\ Vinicius Mothé Maia \\ Doutor em Administração de Empresas pela Pontifícia Universidade Católica do Rio de \\ Janeiro (PUC-RJ). \\ Professor Adjunto da Universidade Federal do Rio de Janeiro (UFRJ). \\ E-mail: viniciusmothemaia@gmail.com
}

\begin{abstract}
RESUMO
Esta pesquisa teve como objetivo averiguar se há diferenças entre as empresas familiares e não familiares e quais seriam essas diferenças do ponto de vista contábil-financeiro. Neste intuito, foram comparadas as empresas listadas no Ibovespa nos anos de 2010 até 2016, sendo as empresas identificadas como familiares classificadas em termos de: gestão, controle e propriedade. Para isso, realizou-se uma análise descritiva de indicadores contábil-financeiros apoiada em uma análise de variância paramétrica e não paramétrica. Os resultados sugerem que, quando existem diferenças significativas entre os grupos, as empresas não familiares são preferíveis às empresas familiares do ponto de vista dos indicadores analisados, por serem melhores opções de investimentos aos agentes de mercado.
\end{abstract}

Palavras-chave: Empresas Familiares. Desempenho. Análise Contábil-Financeira. Conflito de Agência.

\begin{abstract}
The research aimed to investigate if there are differences between the familiar and nonfamiliar companies and what would be these differences from a financial-accounting point of view. For this purpose, the companies listed on the Ibovespa Index were compared, from 2010 to 2016, with the companies identified as familiars classified in terms of: management, control and ownership. For this, a descriptive analysis of financial-accounting indicators was carried out based on a parametric and non-parametric analysis of variance. The results suggest that when there are significant differences between the groups, non-familiar firms are
\end{abstract}


Ettore e Maia (2018)

Análise do Desempenho Contábil-Financeiro das

Empresas Familiares e Não Familiares

preferable to familiar firms from the point of view of the analyzed indicators, thus being better investment options for the market agents.

Key-words: Familiar Companies. Performance. Accounting and Financial Analysis. Agency Conflict.

\section{RESUMEN}

Esta investigación tuvo como objetivo averiguar si hay diferencias entre las empresas familiares y no familiares y cuáles serían esas diferencias desde el punto de vista contablefinanciero. En este sentido, se compararon las empresas listadas en el Ibovespa en los años 2010 hasta 2016, siendo las empresas identificadas como familiares clasificadas en términos de: gestión, control y propiedad. Para ello, se realizó un análisis descriptivo de indicadores contable-financieros apoyados en un análisis de varianza paramétrica y no paramétrica. Los resultados sugieren que, cuando existen diferencias significativas entre los grupos, las empresas no familiares son preferibles a las empresas familiares desde el punto de vista de los indicadores analizados, siendo así mejores opciones de inversión a los agentes de mercado.

Palabras clave: Empresas Familiares. Rendimiento. Análisis Contable-Financiero. Conflicto de Agencia.

\section{INTRODUÇÃO}

Os investidores procuram, de modo geral, identificar as características relevantes que impactam o valor das empresas na busca por vencer o mercado. Duas dessas características são o controle acionário e a gestão empresarial, ou seja, quem controla a organização e quem a gere impacta o resultado da organização (PROCIANOY; CASELANY, 1997).

Nesse contexto, Schulze et al. (2001) abordam que as empresas familiares apresentam características diferenciadas das demais empresas no que se refere ao conflito de agência e ao desempenho financeiro. Cascino et al. (2010) citam que empresas familiares podem ser entendidas como menos eficientes, uma vez que as decisões tomadas podem buscar favorecer não a entidade e sua continuidade, mas a família e seus membros. Além do mais, a busca pela perpetuação no controle pode causar efeitos danosos à entidade como nepotismo ineficiente, onde apenas seriam levados em conta os laços familiares na escolha de cargos relevantes, e também uma gestão não profissional da entidade. Em adição a isso, como abordam Silva et al. (2015), o relacionamento existente entre os membros dos conselhos da organização, os gestores e diretores e os controladores, reduz as atividades de monitoramento, que por sua vez pode diminuir a confiança dos players de mercado para com tal organização.

Por outro lado, há também uma visão em sentido contrário à exposta. As empresas familiares possuem determinadas características que tendem a agradar aos investidores conforme descreve Wang (2006), tais como: certa visão de longo prazo nos negócios, dado que as gerações futuras da família estarão no comando, e além disso, um cuidado com a reputação da entidade, uma vez que o nome da família estaria envolvido (SILVA et al., 2015). Então, em tese, há um maior zelo dos proprietários e gestores com a empresa familiar a partir da preocupação pelo desempenho atual alinhada à ideia de que a empresa será passada para as mãos das futuras gerações da família. 
Todavia, os investidores estão interessados em saber se a empresa lhes entregará os retornos esperados e se otimizará o capital investido. Neste contexto, por apresentarem estruturas de controle, governança e propriedade diferenciados, as empresas familiares e não familiares podem possuir desempenho econômico-financeiro diferentes. A discussão se impõe dado que não há um consenso de que um grupo se sobressaia significativamente sobre o outro. Na literatura, observa-se efeitos positivos da presença familiar nas organizações tais como na qualidade da informação contábil (SILVA et al., 2015), maior criação de valor no desempenho econômico (LUNARDI et al., 2017), menor endividamento (GOES, MARTINS E MACHADO FILHO, 2017) e menor remuneração aos executivos (SANTOS E SILVA, 2018). Por outro lado, efeitos negativos também são vistos, tais como concentração acionária e desempenho inferior (POLITELO E CUNHA, 2014), menor Retorno sobre o Ativo (ROA) em comparação às empresas não familiares (ZBOROWSKI, 2009), menor criação de valor adicionado e potencial de expropriação dos minoritários (BIANCHET et al., 2019), menor lucro operacional e relação com redução do valor da empresa (GOES, MARTINS E MACHADO FILHO, 2017). Além destes estudos, outros apresentam resultados inconclusivos como Scarpin, Almeida e Machado (2012) e Kreuzberg, Cunha e Popik (2016). Assim, devese continuar o aprofundamento sobre o tema, a partir de diferentes frentes, para buscar tal conclusão.

Portanto, esta pesquisa tem como objetivo responder a seguinte questão: do ponto de vista contábil-financeiro, quais são as principais diferenças das empresas familiares e não familiares?

Assim, este estudo almeja elucidar se há diferenças marcantes entre esses dois grupos e quais seriam essas características. Para tanto, lançou-se mão de uma análise descritiva dos dados e de comparações entre os grupos através da Análise de Variância (ANOVA) e do Teste de Mann-Whitney dos indicadores contábil-financeiros.

O estudo se justifica na medida que, como afirmam Villalonga e Amit (2006) e Zborowski (2009), trata de uma temática pouco explorada no contexto da verificação das diferenças entre estes modelos de governança e controle. Além do mais, diversas empresas são controladas ou geridas por famílias no Brasil, incluindo neste conjunto, como cita Zborowski (2009), empresas grandes e consolidadas no mercado, o que reafirma a relevância da pesquisa.

\section{REFERENCIAL TEÓRICO}

Buscou-se na construção da revisão de literatura, apresentar os principais estudos referentes às diferenças entre empresas familiares e não familiares, com foco no desempenho econômico-financeiro. Desta maneira, dividiu-se este tópico em duas partes. Na primeira, explicou-se a noção de empresa familiar, isto é, o que define uma empresa familiar e não familiar. Tal fato se demonstra relevante pois é característica subjacente na diferenciação dos resultados dos grupos.

Ainda nesta parte, foram observados os pontos de possível conflito na governança de uma empresa familiar em comparação a uma empresa não familiar. De posse da ideia de organização familiar e nuances de suas estruturas, foram descritas, na segunda parte do referencial, as pesquisas que abordam temas correlatos, no intuito de fornecer base e parâmetros de comparação para este estudo. 


\subsection{Empresas Familiares}

Em um primeiro momento, necessita-se delimitar a concepção de empresa familiar. Segundo Scarpin, Almeida e Machado (2012), na literatura específica, existem vários conceitos sobre o que seria uma empresa familiar, não possibilitando, portanto, um consenso. Apresenta-se neste tópico, os conceitos que possuem maior consonância. Lodi (1998) relaciona a sucessão da direção da entidade à hereditariedade da família, além do fato dos valores organizacionais estarem intrinsecamente correlacionados ao nome da família e do fundador.

Bernhoeft (1991) cita que a entidade é considerada familiar a partir do momento que a história, nascimento e desenvolvimento desta estão vinculados a uma família. Por fim, Upton, Teal e Felan (2001) abordam que, nas empresas familiares, existe influência da família no processo de tomada de decisões no escopo gerencial, e, principalmente, há o intuito de transferência da entidade, em termos de propriedade e gestão, para a próxima geração.

Em linha com as concepções destes trabalhos, a noção de empresa familiar da presente pesquisa, em termos práticos, coaduna-se com Zborowski (2009), Silva et al. (2015), Kreuzberg, Cunha e Popik (2016) e Politelo e Cunha (2014). Zborowski (2009) e Silva et al. (2015) consideraram a empresa como familiar tanto no que se refere a propriedade e controle quanto a gestão, isto é, a família fundadora pode possuir controle acionário da entidade (maioria das ações com direito a voto), pode ter porcentagem relevante do capital, mas não controlar efetivamente, ou ainda, possuir consanguíneos nos conselhos corporativos e na direção da empresa. Zborowski (2009) depreendeu que possuiria propriedade caso a família possuísse ao menos $5 \%$ do total de ações ordinárias da companhia.

Kreuzberg, Cunha e Popik (2016) utilizou a definição de Setia-Atmaja, Tanewski e Skully (2009): para estes, são familiares "aquelas empresas em que uma família fundadora, ou membro da família, ou um particular controla $20 \%$ ou mais das ações da empresa e que também esteve envolvido na alta gestão da empresa " (KREUZBERG; CUNHA; POPIK, 2016, p. 43). Politelo e Cunha $(2014$, p. 8) delimitaram da seguinte forma a existência da empresa familiar: "concentração de capital votante igual ou superior a $20 \%$ com a família, ou a presença de, ao menos, dois membros da família no conselho de administração da companhia". Desta forma, apesar de haver diferenças entre os três conceitos em certas particularidades, em essência, são similares e delimitam o mesmo objeto.

Todavia, na comparação da estrutura organizacional entre empresas familiares e não familiares, existem alguns pontos que podem ser conflitantes. Conforme Ali, Chen e Radhakrishnan (2007), em relação às empresas familiares, podem existir, essencialmente, dois tipos de conflitos: entre a gestão da entidade e o controle (problema tipo I) e entre o controle da empresa e o interesse dos minoritários (problema tipo II). Como explica Zborowski (2009), no primeiro caso, os gestores da organização podem possuir interesses, pessoais ou profissionais, diferentes dos proprietários. Este fato, por sua vez, pode refletir na ineficácia e no não alcance dos resultados por parte da empresa devido à falta de consonância de interesses. Uma possível solução seria um maior monitoramento e fiscalização dos proprietários sobre os gestores. Desta maneira, viabiliza-se a ideia da presença de membros da família controladora dentro da direção. Além disso, como descreve Wang (2006), a presença, ao longo do tempo, de membros da família fundadora na empresa pode incrementar a qualidade dos resultados. 
No segundo cenário, os controladores podem divergir em suas decisões do que seria mais adequado visando os sócios minoritários, onde estes teriam menor poder decisório na continuidade da corporação e estariam mais vulneráveis quanto às decisões que privilegiariam o grupo familiar. Em resumo, como descrevem Silva et al. (2015), enquanto na resolução do primeiro problema existe a chance de melhora da informação contábil dado o maior controle, na segunda, como afirmam An e Naughton (2009), o que acontece é diminuição da qualidade da informação contábil. Tal fato decorre da possibilidade de assimetria informacional onde as decisões visariam em sua maioria para beneficiar um determinado grupo em detrimento dos sócios minoritários.

Com isso, é relevante examinar os conflitos potenciais quando se possui a presença familiar ou não à luz da avaliação dos resultados contábil-financeiros, uma vez que estes podem ser impactados positiva ou negativamente. Ou seja, conflitos entre as partes interessadas podem interferir nos retornos auferidos.

\subsection{Presença Familiar e Desempenho Contábil-Financeiro}

Como descreverem Lemmon e Lins (2003) a estrutura de propriedade é um dos principais pontos no que se refere o problema de agência, além do mais, esta estrutura impacta no desempenho e no valor das empresas. Assim, como cita Setia-Atmaja, Tanewski e Skully (2009), a concentração de propriedade e a presença familiar ou ausência da mesma podem interferir, de algum modo, nos resultados da empresa.

Desta forma, necessita-se verificar a relação da propriedade, gestão e controle, do ponto de vista da empresa ser familiar ou não familiar, com o desempenho da entidade. A principal forma da avaliação dos resultados empresariais se dá através dos indicadores contábil-financeiros. Como explica Camargos e Barbosa (2005), utilizando-se das demonstrações contábeis como fonte das informações, e transformando tais dados em índices comparáveis, nota-se a evolução do desempenho econômico e financeiro da companhia. Outrossim, pode-se usá-los para avaliação e comparação de grupos de empresas.

Nesta linha, listou-se abaixo alguns trabalhos que convergiram à ideia da análise das empresas familiares e não familiares em relação à informação contábil e os índices contábilfinanceiros. Como contexto geral, tem-se que a literatura procurou verificar os efeitos da presença (ou ausência) familiar de distintas formas. Alguns trabalhos buscaram tal objetivo através da análise de indicadores de desempenho e governança como Zborowski (2009), Politelo e Cunha (2014) e Kreuzberg, Cunha e Popik (2016). Silva et al. (2015), por sua vez, estudaram quais seriam as diferenças na qualidade da informação contábil. Fatores relevantes como lucro e endividamento foram objetos de escrutínio por Scarpin, Almeida e Machado (2012) e Goes, Martins e Machado Filho (2017). Por fim, Santos e Silva (2018) analisaram a remuneração dos executivos destes dois tipos de empresas e Bianchet et al., (2019) compararam a criação do valor adicionado.

Zborowski (2009) analisou as empresas familiares e não familiares presentes no Ibovespa no ano de 2007. Percebeu-se que 42\% das empresas foram classificadas como familiares. Em relação, especificamente, às análises dos resultados econômico-financeiros de Zborowski (2009), tem-se que no que se refere ao retorno sobre o ativo (ROA ou ROI), as empresas não familiares se saíram melhor. Em mão contrária, o retorno sobre o patrimônio líquido (ROE) dos dois grupos de empresas não possibilitaram concluir diferenças entre si. Desta forma, como existem diferenças nas operações da empresa e estas diferenças podem 
impactar no ROI e ROE, não se pode determinar qual dos dois indicadores seria o mais adequado, o que torna inconclusivo o efeito "família" nos retornos. No tocante da variável prêmio de mercado, as empresas familiares apresentaram prêmios de mercado positivos. Vale ressaltar que foi observado que este prêmio é praticamente anulado, se na presença familiar, estiver contida também a gestão familiar.

Scarpin, Almeida e Machado (2012) tiveram como objetivo analisar as diferenças entre empresas familiares e não familiares quanto à lucratividade e o endividamento. O estudo assumiu a premissa inicial de que organizações familiares seriam mais conservadoras. Tal afirmativa estaria correlacionada com um menor endividamento, segundo os autores. A amostra contou com empresas componentes do índice IBrX-100 da Bolsa de Valores de São Paulo correspondente ao período de 2007 a 2009. Os resultados se mostraram inconclusivos, pois não se observou a associação entre gestão familiar e as variáveis lucratividade e endividamento.

Silva et al. (2015) buscaram observar o efeito do controle familiar na qualidade da informação contábil no Brasil. A amostra estudada contemplou as empresas não financeiras de capital aberto no período de 2010 a 2012. Os autores observaram que há um impacto positivo na qualidade da informação contábil, tal fato se justifica pelo lucro das entidades familiares apresentarem maior coeficiente angular do que as organizações classificadas como não familiares. Este fato tem o potencial de reduzir o conflito entre gestão e controle.

Politelo e Cunha (2014) almejaram observar a relação entre a estrutura de propriedade das empresas no que se refere à governança corporativa com o desempenho empresarial das companhias familiares. A amostra estudada conteve 77 empresas abertas entendidas como familiares nos anos de 2010 a 2012. Obteve-se indicadores de que há concentração de capital nas empresas familiares, o que seria característica de países em desenvolvimento, ou ainda com certa falta de proteção dos investidores minoritários. Os autores também constataram, em termos de desempenho, certas discrepâncias dado que enquanto algumas empresas familiares obtiveram resultados contábeis e de mercado bons, outras obtiveram resultados negativos. A estrutura de propriedade e o desempenho apresentaram correlação negativa. Concluiu-se que não há relação relevante entre estrutura de propriedade e desempenho na amostra estudada, ou ainda, que a correlação negativa encontrada poderia demonstrar que estruturas de capital pulverizadas são mais eficientes, dado que estruturas de capital concentradas podem levar a desempenhos inferiores.

Kreuzberg, Cunha e Popik (2016) objetivaram analisar a relação entre o pagamento de dividendos (payout), o nível de endividamento e do conselho de administração com o desempenho financeiro, comparando-se empresas familiares e não familiares. A amostra trabalhada pelo estudo totalizou 220 empresas e compreendeu o ano de 2014. Como resultados, obteve-se que o pagamento de dividendos foi superior nas empresas familiares, diferentemente do nível de dívida, que não foi superior para as empresas familiares. Concluise que a empresa familiar não se utilizou de dividendos e pagamento de dívida para expropriar a riqueza pertencente aos acionistas. Quanto ao tamanho do conselho, os autores observaram que a presença do controle familiar não foi impactante. Por meio do Q de Tobin, visualizou-se que o desempenho das empresas familiares é superior que o das não familiares. Não se observou, com clareza, impacto da estrutura de propriedade sobre as variáveis estudadas.

Lunardi et al. (2017) investigaram a criação de valor no desempenho econômico de empresas familiares e não familiares brasileiras. Os autores utilizaram as empresas listadas 
nos índices IBRX-100 e Ibovespa de 2011 a 2015. De modo geral, o estudo concluiu que empresas familiares possuem maior criação de valor no desempenho econômico ao passo que foi encontrado que as empresas familiares apresentaram resultados melhores no que se refere aos indicadores Economic Value Added (EVA), Market Value Added (MVA), Retorno sobre Ativos (ROA), Retorno sobre o Investimento (ROI).

Goes, Martins e Machado Filho (2017) investigaram o desempenho financeiro das empresas familiares e não familiares listadas em bolsa. Analisou-se o passivo oneroso, lucro operacional líquido e valor da companhia (variáveis dependentes). As variáveis de interesse foram as características da empresa referentes a presença familiar ou não. Em relação ao passivo oneroso, observou que a presença familiar contribui para o menor uso de capital de terceiros. As empresas não familiares se sobressaíram em relação ao lucro operacional e valor da empresa. Já Santos e Silva (2018) verificaram se a presença familiar possui relação com a remuneração executiva. Analisando as empresas abertas de 2010 a 2016, observaram que a remuneração total e variável são menores para empresas familiares.

Bianchet et al. (2019) buscaram identificar as diferenças na geração e distribuição do valor adicionado entre empresas familiares e não familiares. Utilizou-se das empresas listadas na Bolsa de Valores de São Paulo de 2013 a 2015. Os resultados do trabalho sugerem que as empresas não familiares criam e distribuem maior quantidade de valor adicionado (em quatro grupos: pessoal, tributos, remuneração de capital de terceiros e remuneração de capital próprio). Os autores concluem que a gestão familiar pode ter potencial de expropriar os minoritários.

\section{METODOLOGIA}

A pesquisa se caracteriza como descritiva, dado que, conforme Andrade (2004), utiliza-se dos dados selecionados na sua análise e interpretação, sem interferir diretamente nos mesmos. Observando-se o método de abordagem da pesquisa em relação ao problema a ser respondido, o estudo, conforme Soares (2003) é quantitativo, pois há o emprego de técnicas estatísticas na leitura dos dados. Segundo Lakatos e Marconi (2001) a pesquisa é documental em relação ao método de coleta das informações, isto é, reuniu-se informações a partir de documentos e registros. Vale lembrar que tomando como parâmetro as próprias empresas e seus documentos e demonstrações contábeis, esta pesquisa fez uso de dados secundários, uma vez que as fontes utilizadas transformaram os dados daquelas empresas.

\subsection{Delimitação do conceito de empresa familiar}

O ponto de partida para a pesquisa e a própria análise dos dados foi a delimitação do que é uma empresa familiar. Tal delimitação também se mostra relevante devido à complexidade de estruturas das empresas abertas. Recorrendo ao Referencial Teórico construído e refletindo sobre os conceitos descritos por Anderson e Reeb (2003), Wang (2006), Zborowski (2009), Politelo e Cunha (2014), Silva et al. (2015) e Kreuzberg, Cunha e Popik (2016), esta pesquisa considera uma empresa familiar se satisfizer um dos seguintes pontos:

i) Em termos de controle: buscou-se identificar a pessoa física controladora, seja diretamente no controle da empresa, seja aprofundando-se no controle da pessoa jurídica controladora até se chegar a pessoas físicas. Isto é, existirá o controle familiar, se, no caso de 
pessoa física, o controlador tiver o mesmo sobrenome do fundador da empresa, ou, no caso de o controlador ser pessoa jurídica, a holding ser controlada por uma pessoa com o mesmo sobrenome do fundador. No caso de a empresa controladora ser também controlada por outra pessoa jurídica, esmiuçou-se a posição acionária destas até se chegar a pessoas físicas. No caso de a holding possuir vários sócios, foi considerada familiar, se somando-se as posições de todos aqueles com o mesmo sobrenome do fundador, existir o controle da sociedade. Dizse controlador, aquele que possuir maioria das ações com poder de voto, ou seja, pelo menos $50 \%$ mais uma ação do total de ações ordinárias, como descrevem Anderson e Reeb (2003) e Wang (2006).

ii) Em termos de propriedade: compreende a mesma ideia do item anterior, todavia, não existe o controle, mas sim a influência na empresa e suas operações. A porcentagem mínima da posição acionária para se definir a propriedade é de $20 \%$. Fez-se deste modo, baseando-se na concepção de influência significativa, descrita pelo CPC 18 (2012, p. 2), que seria "poder de participar das decisões sobre políticas financeiras e operacionais de uma investida, mas sem que haja o controle individual ou conjunto dessas políticas". No mesmo pronunciamento técnico contábil, utiliza-se a porcentagem mínima de $20 \%$ para quantificar a influência significativa. Ressalta-se que Kreuzberg, Cunha e Popik (2016) e Politelo e Cunha (2014) também utilizaram este valor.

iii) Em termos de gestão: analisou-se o Conselho de Administração e a Diretoria. É classificada como empresa familiar aquela que possuir ao menos $20 \%$ dos membros do Conselho de Administração e/ou o Presidente do Conselho ou da Diretoria e/ou o DiretorPresidente com o mesmo sobrenome que o fundador. A ideia de a composição do Conselho de Administração estar correlacionado com a presença familiar também foi descrita por Anderson e Reeb (2003).

Os dados necessários a essa classificação foram coletados no Formulário de Referência, um dos relatórios financeiros disponibilizados no site da BM\&FBovespa, e no sítio eletrônico EconoInfo, que sintetiza diversas informações das companhias abertas brasileiras. Esses dados a respeito da posição acionária, composição do Conselho de Administração e composição da Diretoria tiveram como referência maio de 2017.

\subsection{Amostra e variáveis estudadas}

Para se atingir o objetivo do artigo, foram coletados alguns indicadores contábilfinanceiros e de mercado. Seguem na Tabela 1 os principais índices analisados e suas descrições:

Tabela 1 - Principais Indicadores

\begin{tabular}{|c|c|}
\hline $\begin{array}{c}\text { Retorno do Capital } \\
\text { Investido }\end{array}$ & $\begin{array}{c}\text { Indica a efetividade da empresa no uso de suas fontes de recursos } \\
\text { (próprio e de terceiros). Divide-se o NOPAT (lucro operacional após } \\
\text { os impostos) pelo capital total investido. }\end{array}$ \\
\hline Dívida Líquida/EBITDA & $\begin{array}{c}\text { Mostra a capacidade de pagamento das obrigaçôes com terceiros } \\
\text { através do potencial de caixa gerado. Quanto maior este coeficiente, } \\
\text { mais elevado o endividamento da empresa. }\end{array}$ \\
\hline EBITDA & $\begin{array}{c}\text { É o lucro antes dos juros, impostos, depreciação e amortização. } \\
\text { Busca, de maneira geral, verificar a capacidade operacional da } \\
\text { organização na geração de caixa. }\end{array}$ \\
\hline Crescimento das Vendas & $\begin{array}{c}\text { Aumento ou diminuição das vendas comparadas ao ano anterior. } \\
\text { Indica tendências de melhora ou piora dos resultados do negócio. }\end{array}$ \\
\hline Dividend Yield & Demonstra a rentabilidade dos dividendos tendo como parâmetro a \\
\hline
\end{tabular}


Análise do Desempenho Contábil-Financeiro das

Empresas Familiares e Não Familiares

\begin{tabular}{|c|c|}
\hline & $\begin{array}{r}\text { ação da empresa. É, portanto, o quanto as ações geram de renda } \\
\text { (dinheiro) ao proprietário em um ano. }\end{array}$ \\
\hline
\end{tabular}

Fonte: Bloomberg e Assaf Neto (2014).

A amostra compreende as empresas componentes da carteira do índice Ibovespa nos anos de 2010 até 2016. Os indicadores de tais empresas foram coletados na Plataforma Bloomberg. Foram excluídas as ações das empresas que aparecem mais de uma vez, e também foi retirada uma ação referente à Bolsa de Valores. Para o indicador Dívida Líquida/EBITDA, foram excluídas as empresas financeiras devido ao fato de que sua atividade operacional é contrair dívida, o que poderia distorcer a análise. Por fim, excluiu-se as empresas que eram controladas por outra empresa que também compunha a amostra, ficouse assim com a controladora dado que a empresa controlada compõe os resultados da controladora e que a classificação familiar em termos de gestão, propriedade e controle seria duplicada.

\subsection{Métodos}

A análise em si, primeiramente, perpassou pela verificação das principais características da amostra como um todo, do grupo de empresas familiares e de não familiares em cada ano por meio de estatística descritiva. Posteriormente, examinou-se as diferenças dos dois grupos estudados em cada ano, observando similaridades e tendências entre os anos.

Para corroborar à análise das diferenças entre as empresas familiares e não familiares, realizou-se uma Análise de Variância (ANOVA) entre os dois grupos em cada ano para cada indicador a um nível de significância de 5\%. Assim, pretendeu-se observar se nestes casos a hipótese nula seria rejeitada, que conforme Stevenson (2001), no caso de dois conjuntos amostrais, seria quando uma das médias é diferente da outra, permitindo averiguar se os grupos são similares ou não entre si. Além do mais, buscando eliminar ou relaxar alguma possível incompatibilidade da amostra com os pressupostos estatísticos da ANOVA, como a normalidade amostral ou tamanho da amostra, aplicou-se também o teste não paramétrico de Mann-Whitney (U), no intuito de confirmar os resultados encontrados do teste anterior. Os dois testes foram realizados no software SPSS.

A análise entre as empresas familiares e não familiares considerou a classificação proposta, comparou-se então essa diferenciação em relação à posição acionária (controle e propriedade) e gestão. Buscou-se, através disso, verificar possíveis diferenças entre as classificações que agreguem e lapidem o estudo dos resultados no sentido de reduzir distorções ou pontos não explicados pela análise geral.

Por fim, buscou-se examinar o possível conflito de agência existente entre gestão da entidade e o controle (problema tipo I) que poderia acontecer em organizações familiares. Para isso, utilizou-se apenas as empresas familiares, e se dividiu a amostra em dois grupos, das empresas que foram classificadas familiares em termos de gestão e outro que não (vale lembrar que estes dois grupos já são classificados familiares em termos de controle e/ou propriedade). Analisou-se, então, se o grupo familiar pela classificação da gestão possui melhores resultados econômico-financeiros que o outro. Se tal hipótese for atendida, compreende-se que, como descreve Silva et al. (2015), o monitoramento pela família ajuda na solução do problema I, ou seja, na redução da assimetria informacional, na melhora da informação contábil, e por sua vez, potencializa o desempenho das empresas familiares. 


\section{RESULTADOS}

\subsection{Perfil da Amostra e Análise Descritiva}

$\mathrm{Na}$ análise foram coletadas as informações e indicadores contábil-financeiros das empresas que compunham o índice Ibovespa nos anos estudados. Ao todo, foram observadas 77 empresas, de modo que certas empresas faziam parte do Ibovespa em alguns anos, e em outros não. Através dos critérios utilizados para classificação das empresas apresentados na seção anterior, chegou-se a um total de 33 empresas familiares e 44 empresas não familiares, conforme Tabela 2.

Tabela 2 - Características da Amostra

\begin{tabular}{cccccccccc}
\hline \multirow{2}{*}{ Classificação } & \multicolumn{2}{c}{ Controle } & \multicolumn{2}{c}{ Propriedade } & \multicolumn{2}{c}{ Gestão } & \multicolumn{2}{c}{ Geral } \\
\cline { 2 - 9 } & Abs. & \% & Abs. & \% & Abs. & \% & Abs. & \% \\
\hline Familiar & 14 & $18,2 \%$ & 17 & $22,1 \%$ & 21 & $27,3 \%$ & 33 & $42,9 \%$ \\
Não Familiar & 63 & $81,8 \%$ & 60 & $77,9 \%$ & 56 & $72,7 \%$ & 44 & $57,1 \%$ \\
\hline
\end{tabular}

Fonte: Elaborado a partir dos dados da pesquisa.

Assim, tem-se que somando as 14 empresas entendidas como familiares por serem controladas, mais as 17 empresas que detém propriedade, mais as 2 empresas que não tinham sido classificadas como familiares pela posição acionária (controle ou propriedade, dado que são mutuamente excludentes) mas que tenham sido categorizadas apenas pela gestão, chegase ao total de 33 empresas familiares. Importante ressaltar que a classificação pela gestão não é excludente à classificação da posição acionária, dessa forma, das 21 empresas que foram classificadas familiares quanto à gestão, 19 também foram classificadas quanto à posição acionária e das 14 restantes, 12 foram categorizadas apenas quanto à posição acionária.

$\mathrm{Na}$ Tabela 3, pode-se observar a classificação ano a ano com o número de empresas familiares e não familiares. Visualiza-se uma constância na proporção de familiares e não familiares no Ibovespa dada a similaridade dos números. A ideia da utilização de um período mais longo é verificar como as variáveis estudadas se comportam ao longo do tempo.

Tabela 3 - Características da Amostra em cada ano

\begin{tabular}{cccccccc}
\hline Classificação & $\mathbf{2 0 1 0}$ & $\mathbf{2 0 1 1}$ & $\mathbf{2 0 1 2}$ & $\mathbf{2 0 1 3}$ & $\mathbf{2 0 1 4}$ & $\mathbf{2 0 1 5}$ & $\mathbf{2 0 1 6}$ \\
\hline Familiar & 21 & 22 & 24 & 25 & 24 & 24 & 22 \\
Não Familiar & 33 & 33 & 34 & 35 & 36 & 31 & 27 \\
\hline
\end{tabular}

Fonte: Elaborado a partir dos dados da pesquisa.

Vale ressaltar que das empresas categorizadas como não familiares, 7 (15,9\%) são empresas estatais, assim, não foram fundadas em um primeiro momento com o intuito de empresa. Todavia, como as empresas familiares são o foco, seria esperado que a classificação de organização não familiar fosse conter características diversas, sendo uma delas o das instituições de Estado, uma vez que essas não são geridas por interesses de grupos específicos, em tese.

Em adição ao conceito de família exposto na metodologia, ressalta-se que se a empresa não possuísse um fundador, ou seja, era estatal e posteriormente foi privatizada ou ainda que tenha sido criada por algum conglomerado econômico, e na sua estrutura de administração e controle/propriedade acionária tenha diversas pessoas com o mesmo 
sobrenome, esta empresa foi considerada familiar. Tal classificação se baseia na ideia de que o fundamento do criador de uma organização utilizar de familiares é o mesmo que nos casos descritos acima, onde houve a passagem do controle acionário ou administrativo e o responsável fez uso disso para adicionar familiares na estrutura organizacional.

No tocante à gestão, foram analisados o Conselhos de Administração (C. A.) e Diretoria. O Conselho de Administração seria onde se delimitam os principais nortes estratégicos da organização, enquanto a Diretoria seria o elo entre o C. A. e as operações propriamente ditas, ao passo que ambos são fundamentais para a empresa. Neste estudo, praticamente todas as empresas entendidas como familiares possuem alguns de seus membros em pelo menos um desses boards.

Das empresas familiares, $20(60,6 \%)$ não possuem familiares na direção, por outro lado, falando do Conselho de Administração, apenas 30,3\% das empresas familiares não têm consanguíneos do primogênito fundador neste board, além de que 10 das empresas familiares apresentam um familiar como Presidente do Conselho de Administração. Além disso, 8 das 13 empresas que possuem familiares na Diretoria, tem este como Diretor-Presidente. Percebese, portanto, que os proprietários das organizações familiares, seja controlando, seja tendo influência significativa, preferem ter um dos seus no corpo pensante e deliberativo do que no quadro mais executivo. Logo, objetiva-se mais decidir os rumos do negócio que pertence a família do que decisões mais ligadas às operacionalidades. Por outro lado, quando estas organizações detêm familiares que fazem parte da Diretoria, é possível que tal situação se dê no intuito de ter a decisão mais poderosa e influente.

\subsection{Diferenças entre Companhias Familiares e Não Familiares}

A análise das diferenças entre companhias familiares e não familiares se dá por cinco frentes, cada uma delas medida por um índice: o retorno do investimento; a capacidade da empresa de pagar suas obrigações firmadas com terceiros; o potencial da instituição de fazer caixa; a variação das vendas dos produtos, e por fim, o quanto a empresa consegue retornar ao acionista que detém a ação daquela entidade.

Tabela 4 - Análise de Médias das Empresas Familiares e Não Familiares

\begin{tabular}{|c|c|c|c|c|c|c|c|c|c|}
\hline & Análise & & 2010 & 2011 & 2012 & 2013 & 2014 & 2015 & 2016 \\
\hline \multirow{4}{*}{ ROIC } & \multicolumn{2}{|c|}{ Familiar } & 7,16 & 6,72 & 6,36 & $-3,99$ & $-17,63$ & 6,33 & 6,75 \\
\hline & \multicolumn{2}{|c|}{ Não Familiar } & 16,79 & 14,02 & 10,22 & 8,05 & 7,65 & 5,94 & 8,05 \\
\hline & \multirow{2}{*}{ p-valor } & ANOVA & $0,05^{* *}$ & $0,08 *$ & 0,24 & 0,17 & 0,23 & 0,89 & 0,54 \\
\hline & & Teste U & $0,02 * *$ & $0,02 * *$ & 0,23 & 0,61 & 0,90 & 0,42 & 0,97 \\
\hline \multirow{4}{*}{$\begin{array}{l}\text { Dívida/ } \\
\text { EBITDA }\end{array}$} & \multicolumn{2}{|c|}{ Familiar } & 3,57 & 8,08 & 4,77 & 5,30 & 3,98 & 6,17 & 5,18 \\
\hline & \multicolumn{2}{|c|}{ Não Familiar } & 2,36 & 2,88 & 3,41 & 5,06 & 10,18 & 4,69 & 3,55 \\
\hline & \multirow{2}{*}{ p-valor } & ANOVA & $0,03 * *$ & $0,00 * * *$ & 0,32 & 0,91 & 0,23 & 0,49 & 0,20 \\
\hline & & Teste U & $0,01 * * *$ & $0,00 * * *$ & 0,13 & 0,20 & 0,33 & 0,18 & 0,19 \\
\hline \multirow{4}{*}{ EBITDA } & \multicolumn{2}{|c|}{ Familiar } & $2.318,67$ & $1.700,75$ & $1.357,22$ & $1.113,42$ & $2.160,06$ & $2.548,14$ & $2.577,90$ \\
\hline & \multicolumn{2}{|c|}{ Não Familiar } & $5.734,87$ & $6.477,85$ & $4.833,56$ & $5.618,57$ & $3.874,31$ & $3.451,39$ & $7.933,30$ \\
\hline & \multirow{2}{*}{ p-valor } & ANOVA & 0,25 & 0,15 & 0,14 & 0,11 & 0,18 & 0,61 & 0,13 \\
\hline & & Teste U & 0,16 & $0,06^{*}$ & 0,11 & 0,26 & 0,28 & 0,26 & $0,09 *$ \\
\hline
\end{tabular}


Ettore e Maia (2018)

Análise do Desempenho Contábil-Financeiro das Empresas Familiares e Não Familiares

\begin{tabular}{|c|c|c|c|c|c|c|c|c|c|}
\hline \multirow{4}{*}{$\begin{array}{l}\text { Cresc. } \\
\text { Vendas }\end{array}$} & \multicolumn{2}{|c|}{ Familiar } & 31,49 & 13,91 & 8,72 & 15,84 & 6,42 & 7,81 & 5,00 \\
\hline & \multicolumn{2}{|c|}{ Não Familiar } & 18,99 & 14,74 & 21,14 & 2,96 & 11,78 & 16,38 & 0,12 \\
\hline & \multirow{2}{*}{ p-valor } & ANOVA & 0,17 & 0,86 & 0,42 & $0,07^{*}$ & 0,39 & 0,53 & 0,26 \\
\hline & & Teste U & $0,02 * *$ & 0,61 & 0,21 & $0,10^{*}$ & 0,58 & 0,85 & 0,29 \\
\hline \multirow{4}{*}{$\begin{array}{l}\text { Dividend } \\
\text { Yield }\end{array}$} & \multicolumn{2}{|c|}{ Familiar } & 38,67 & 38,49 & 2,40 & 2,50 & 2,67 & 4,73 & 2,68 \\
\hline & \multicolumn{2}{|c|}{ Não Familiar } & 3,78 & 3,52 & 3,99 & 3,65 & 4,55 & 5,21 & 4,16 \\
\hline & \multirow{2}{*}{$\mathrm{p}$-valor } & ANOVA & 0,28 & 0,27 & 0,21 & 0,31 & 0,14 & 0,87 & 0,48 \\
\hline & & Teste U & 0,31 & 0,67 & 0,37 & 0,71 & 0,34 & 0,24 & 0,89 \\
\hline
\end{tabular}

Significância: $* * * 1 \%, * * 5 \% \mathrm{e} * 10 \%$.

Nota: EBITDA: em milhões de reais; ROIC e Cresc. Vendas: em \%.

Fonte: Elaborado a partir dos dados da pesquisa.

A Tabela 4 apresenta essas variáveis por ano para cada um dos grupos de empresas estudadas. Examinando as médias, detém-se que, exceto no ano de 2015, as empresas não familiares se saíram melhores. Apesar disso, como se observa pelo p-valor da Análise de Variância, na maioria dos casos, são superiores ao nível de significância de $10 \%$, o que demostra que os grupos não possuem diferenças estatisticamente relevantes do ponto de vista do desempenho em se tratando de Retorno sobre o Capital Investido. Vale citar que nos dois primeiros anos existiram diferenças estatisticamente significativas ao nível de 5\% e 10\%, respectivamente, nesses dois casos, as empresas não familiares obtiveram desempenho superior às empresas familiares. O teste de Mann-Whitney, corroborou aos achados da ANOVA, onde nos dois primeiros anos os dois grupos possuíram desempenhos estatisticamente diferentes a 5\%, ao contrário dos demais anos.

Em relação à capacidade de pagamento da empresa em comparação ao seu potencial de gerar caixa, utilizou-se a dívida com terceiros sobre o EBITDA (Lucro antes dos Juros, Impostos, Depreciação e Amortização). Desta maneira, quanto maior este coeficiente, mais endividada estaria a empresa. Não foi observado nenhum caso onde este indicador estivesse negativo, tal fato distorceria a análise do mesmo. Nos primeiros dois anos, como se vê na Tabela 4, as empresas familiares se mostraram com desempenho estatisticamente diferente e inferior às empresas não familiares a $1 \%$ pela Teste U e $5 \%$ e $1 \%$ pela ANOVA, respectivamente. Em 2012, 2013, 2014 e 2016 apesar das empresas não familiares possuírem médias menores (para este indicador quanto menor, melhor), tanto a ANOVA quando o Teste U não encontraram diferenças estatisticamente significativas nem a 10\%. Em 2015, apesar das empresas familiares terem média menor, não se observou diferenças estatísticas.

Observando o denominador do indicador anterior, ou seja, o quanto a empresa pode ganhar em um período em termos financeiros, sem as influências de despesas financeiras, impostos, depreciação e amortização (despesas econômicas - sem impacto no caixa). Assim como no índice anterior, no EBITDA propriamente dito, conforme Tabela 4, as empresas não familiares possuem médias mais elevadas, analisando descritivamente. Ressalta-se que ao nível de 5\% de significância, ou mesmo de 10\%, pela ANOVA, os dois grupos não apresentam diferenças estatisticamente relevantes neste indicador. Da mesma forma que no primeiro indicador, quando se esteve mais perto da diferença significante, o grupo melhor seria o não familiar. Vale destacar, porém, que pelo Teste de Mann-Whitney, em 2011 e 2016, existiu diferença estatisticamente relevante a $10 \%$ entre os grupos, onde as empresas não familiares se saíram melhores. 
Um indicador de grande relevância e não propriamente contábil é a variação de volume de vendas, o quanto a empresa está expandindo no mercado e conquistando mais clientes. Dado que se observa 7 anos, pode-se visualizar na Tabela 4 uma tendência de queda, o que acontece com os dois grupos, pode-se supor, então, que as quedas são advindas da recessão macroeconômica que o país passou nos anos estudados, especialmente os últimos, com retração da atividade produtiva. Em três anos, as empresas familiares foram melhores em média, do mesmo modo que em outros três as organizações não familiares obtiveram melhores resultados. Contudo, nenhuma das diferenças nos resultados foi estatisticamente significante a 5\% (apenas em 2013 houve indicação de diferença estatisticamente significativa a $10 \%$, onde as empresas familiares foram melhores). Desta vez, quando se esteve perto de existirem diferenças entre os tipos de organizações, as empresas familiares se sairiam melhores. Através do Teste U, observou-se que nos anos de 2010 e 2013, os grupos obtiveram desempenhos diferentes a $5 \%$ e $10 \%$, respectivamente. Nestes anos, as empresas familiares se apresentaram superiores.

Por fim, o Dividend Yield retrata a ótica do acionista, por ser a rentabilidade relativa dos dividendos em comparação ao preço da ação. Nos quatro últimos anos, as empresas não familiares apresentaram médias superiores, entretanto, não se verificou diferença estatística. Já nos dois primeiros, as empresas familiares obtiveram médias maiores com certa folga e mesmo assim sem significância em termos estatísticos. Isto se deve ao fato da existência de uma empresa outlier que obteve Dividend Yield bem superior aos demais. Basta observar a mediana, medida de tendência central que não é influenciada por extremos, como é o caso da média. Nestes dois anos, as medianas das empresas familiares foram 2,15 e 2,42, em 2010 e 2011, respectivamente. Este fato corrobora com a análise dos outros anos e com a ANOVA. O Teste U confirma estas afirmações supracitadas ao não encontrar significância estatística nestes anos e também nos demais, assim como a ANOVA.

Em síntese, comparando as médias, no geral, as empresas não familiares se saíram melhores nos campos do retorno monetário do acionista (DY), Dívida/EBITDA, EBITDA e Retorno sobre o Capital Investido (ROIC), sugerindo que uma postura não familiar seria mais efetiva, sem a existência de questões como o interesse particular em detrimento da sociedade empresarial e a necessidade de se passar a empresa para outras gerações. Neste sentido, os resultados encontrados estão em consonância com os estudos de Scarpin, Almeida e Machado (2012) e Kreuzberg, Cunha e Popik (2016) no sentido da inconclusão das diferenças entre os grupos, e corrobora em certo grau com Zborowski (2009) e Politelo e Cunha (2014), , Goes, Martins e Machado Filho (2017) e Bianchet et al. (2019) na ideia das empresas não familiares se saírem superiores de alguma maneira uma vez que, neste trabalho, quando houve diferenças significativas entre os grupos, as empresas não familiares se saíram melhores.

Entretanto, apesar de algumas exceções em alguns dos anos, não se observou, de modo geral, diferenças estatisticamente relevantes entre estes dois grupos, ou seja, os resultados se deram de tal modo que nenhum dos dois grupos se sobressaiu em grande escala, com significância estatística, sobre o outro. Importante fazer o adendo a este contraponto que, como já explicado, quando um grupo superou o outro, em regra, este primeiro foi o grupo não familiar.

As análises das diferenças entre as empresas familiares e não familiares em relação à posição acionária (controle e propriedade) e gestão não se fizeram possíveis, pois apenas 2 empresas foram classificadas como familiares pela gestão e sem controle ou propriedade, o 
que inviabiliza a análise, uma vez que as amostras, na ANOVA e no Teste U, se dariam entre um grupo de 12 empresas (empresas classificadas apenas pela posição acionária) e outro de 2. Ressalta-se que esta ideia buscaria verificar diferenças entre empresas classificadas como familiares apenas pela posição acionária em comparação com empresas familiares em termos apenas de gestão. Outro ponto que deve ser notado se refere ao fato de que estes números são da amostra total de empresas, entretanto, como já foi exposto, os números de empresas familiares e não familiares ao longo dos anos se comportam de maneira razoavelmente uniforme e um pouco abaixo dos valores totais, o que inviabilizaria ainda mais esta análise complementar.

\subsection{Diferenças entre Gestão Familiar e Não Familiar}

Enfim, analisou-se se a presença de membros familiares na gestão da empresa (Conselho de Administração e Diretoria) pode atenuar ou eliminar o conflito de agência referente à possibilidade dos administradores e gestores trabalharem de modo que se distanciem dos objetivos dos proprietários e busquem satisfazer os interesses próprios. Observou-se, então, as médias e o p-valor da Análise de Variância e do Teste de MannWhitney de dois grupos: um que seria classificado como familiar quanto à posição acionária e também quanto à gestão (na Tabela 5 , "C/ Gestão Fam.") e outro que também seja familiar pela posição acionária, mas que não seja pela gestão ("S/ Gestão Fam.). Logo, tem-se dois grupos onde os proprietários, controladores ou não, são familiares, onde um deles, a família também está representada na gestão, que pode ser monitorada pelos membros familiares, no outro grupo de empresas, não pode.

Tabela 5 - Análise de Médias das Gestões Familiares e Não Familiares

\begin{tabular}{|c|c|c|c|c|c|c|c|c|c|}
\hline \multicolumn{3}{|c|}{ Análise } & 2010 & 2011 & 2012 & 2013 & 2014 & 2015 & 2016 \\
\hline \multirow{2}{*}{$\begin{array}{l}\text { Quant. de } \\
\text { Empresas }\end{array}$} & \multirow{2}{*}{\multicolumn{2}{|c|}{$\begin{array}{l}\text { C/ Gestão Fam. } \\
\text { S/ Gestão Fam. }\end{array}$}} & 10 & 12 & 14 & 15 & 16 & 16 & 14 \\
\hline & & & 9 & 8 & 9 & 9 & 7 & 7 & 7 \\
\hline \multirow{4}{*}{ ROIC } & \multirow{2}{*}{\multicolumn{2}{|c|}{$\begin{array}{l}\text { C/ Gestão Fam. } \\
\text { S/ Gestão Fam. }\end{array}$}} & 4,86 & 4,96 & 5,85 & 6,35 & 6,83 & 4,68 & 5,36 \\
\hline & & & 9,97 & 9,35 & 6,18 & $-23,14$ & $-77,33$ & 9,97 & 9,34 \\
\hline & \multirow{2}{*}{$\mathrm{p}$-valor } & ANOVA & 0,30 & 0,30 & 0,95 & 0,14 & 0,14 & 0,29 & 0,27 \\
\hline & & Teste U & 0,57 & 0,45 & 0,79 & 0,78 & 0,47 & $0,09 *$ & 0,12 \\
\hline \multirow{4}{*}{$\begin{array}{l}\text { Dívida/ } \\
\text { EBITDA }\end{array}$} & \multirow{2}{*}{\multicolumn{2}{|c|}{$\begin{array}{l}\text { C/ Gestão Fam. } \\
\text { S/ Gestão Fam. }\end{array}$}} & 3,79 & 10,38 & 5,55 & 6,37 & 4,35 & 6,69 & 6,04 \\
\hline & & & 3,17 & 3,95 & 3,20 & 2,80 & 2,86 & 4,88 & 3,31 \\
\hline & \multirow{2}{*}{$\mathrm{p}$-valor } & ANOVA & 0,45 & 0,17 & 0,39 & 0,24 & 0,19 & 0,65 & 0,28 \\
\hline & & Teste U & 0,28 & $0,08^{*}$ & 0,35 & $0,03 * *$ & 0,11 & 0,48 & 0,14 \\
\hline \multirow{4}{*}{ EBITDA } & \multirow{2}{*}{\multicolumn{2}{|c|}{$\begin{array}{l}\text { C/ Gestão Fam. } \\
\text { S/ Gestão Fam. }\end{array}$}} & $1.978,38$ & $1.734,4$ & $1.288,18$ & $1.713,90$ & $2.025,46$ & $2.033,00$ & $1.928,12$ \\
\hline & & & $2.819,71$ & $1.636,24$ & $1.478,03$ & $-12,48$ & $2.518,99$ & $3.921,87$ & $3.985,74$ \\
\hline & \multirow{2}{*}{ p-valor } & ANOVA & 0,50 & 0,91 & 0,78 & 0,34 & 0,69 & 0,23 & 0,16 \\
\hline & & Teste U & 0,51 & 0,61 & 0,68 & 0,85 & 0,21 & 0,12 & $0,02 * *$ \\
\hline Cresc. & $\mathrm{C} / \mathrm{Ges}$ & tão Fam. & 36,15 & 12,60 & 12,69 & 8,48 & 3,76 & 6,89 & 3,53 \\
\hline
\end{tabular}


Ettore e Maia (2018)

Análise do Desempenho Contábil-Financeiro das

Empresas Familiares e Não Familiares

\begin{tabular}{cccccccccc} 
Vendas & S/ Gestão Fam. & 30,38 & 17,11 & 2,68 & 29,99 & 2,51 & 8,61 & 5,83 \\
\cline { 2 - 9 } & \multirow{2}{*}{ p-valor } & ANOVA & 0,91 & 0,47 & 0,55 & 0,11 & 0,66 & 0,89 & 0,85 \\
& Teste U & 0,49 & 0,37 & 0,80 & 0,11 & 0,82 & 0,73 & 0,82 \\
\hline \hline \multirow{2}{*}{$\begin{array}{c}\text { Dividend } \\
\text { Yield }\end{array}$} & \multirow{2}{*}{ C/ Gestão Fam. } & 1,59 & 2,19 & 1,96 & 1,99 & 2,09 & 2,83 & 1,74 \\
\cline { 2 - 10 } & \multirow{2}{*}{ S/ Gestão Fam. } & 4,39 & 3,73 & 2,59 & 2,52 & 3,03 & 4,53 & 3,10 \\
\hline \multirow{2}{*}{ p-valor } & ANOVA & 0,44 & 0,56 & 0,80 & 0,98 & 0,65 & 0,91 & 0,55 \\
& Teste U & 0,84 & 0,80 & 0,66 & 1,00 & 0,64 & 0,19 & 0,19 \\
\hline
\end{tabular}

Significância: $* * * 1 \%$, ** 5\% e *10\%.

Nota: EBITDA: em milhões de reais; ROIC e Cresc. Vendas: em \%.

Fonte: Elaborado a partir dos dados da pesquisa.

Em um primeiro momento, examinando apenas as médias, obteve-se que, o grupo com posição acionária familiar e sem gestão familiar apresentou, apesar de algumas exceções, maiores valores médios ao longo dos anos nos indicadores Retorno sobre o Capital Investido, Dívida/EBITDA, EBITDA, Crescimento de Vendas (o mais acirrado, onde dos 7 anos, este grupo obteve maiores médias em 4) e Dividend Yield.

Todavia, como se observa na Tabela 5, na maioria dos casos, os desempenhos dos dois grupos são indiferentes estatisticamente ao nível de significância de até $10 \%$ pela ANOVA. Vale pontuar que, pelo Teste U, nestes casos: em 2015 no indicador ROIC a 10\%, em 2011 e 2013 no indicador Dívida/EBITDA a 10\% e 5\%, respectivamente e em 2016 no indicador EBITDA a 5\%, houve diferença estatisticamente relevante entre os grupos e em todos as situações o grupo familiar sem gestão familiar obteve melhores resultados.

Desta maneira, os resultados, em geral, estão em discordância com a hipótese levantada por Silva et. al (2015), que afirmaram que este monitoramento tem o potencial de solucionar o problema I (conflito da agência supracitado), isto é, esta ingerência familiar sobre o negócio poderia alinhar possíveis conflitos de interesses e tal fato afetaria positivamente a companhia e seus resultados. Como estatisticamente se observou indiferença entre as médias, também não se pode refutar a hipótese descrita, sob o prisma da ANOVA. Pelo Teste de Mann-Whitney, em poucos casos, pode-se observar piora de desempenho com a presença familiar na gestão, estatisticamente significativa a 5\% ou 10\%.Nas demais situações, a análise deste teste é semelhante à ANOVA.

Finalmente, comparando as médias descritivamente e as situações onde houve desempenhos estatisticamente diferentes, nota-se uma relação importante nestas análises feitas: os resultados do grupo com gestão familiar guardam alguma correlação com os resultados das empresas familiares da análise geral, do mesmo modo, os resultados do grupo sem gestão familiar são correlatos aos resultados do grupo não familiar da análise geral. Isto é, os grupos não familiares e familiares sem gestão familiar, na grande maioria dos casos, obtiveram médias superiores, e quando houve diferença estatística entre os grupos, estes dois grupos se saíram melhores, em geral. Tal perspectiva sugere que a presença da família nos negócios poderia ser danosa ao desempenho, pois como se observou, os grupos que continham menos familiares se mostraram com melhor desempenho.

\section{CONCLUSÃO}


Este trabalho almejou analisar e comparar as principais diferenças entre as empresas familiares e não familiares sob à luz de indicadores contábil-financeiros. Para isto, observouse os dois grupos de empresas listadas no índice Ibovespa de 2010 a 2016 . A concepção de empresa familiar foi definida em termos de gestão, controle e propriedade, onde a partir de parâmetros propostos se delimitou o grupo de empresas entendido como familiar.

Examinou-se então os dois grupos de organizações pelo seu retorno do negócio como um todo, seu grau de endividamento em relação à sua capacidade de gerar caixa em um ano, o próprio potencial anual de gerar caixa, a variação de vendas em comparação ao ano anterior e, por fim, mediu-se o quanto a empresa retorna em proventos ao acionista. Portanto, fornece-se uma avaliação diversificada e que verifica vários pontos essenciais a um investidor interessado.

Os resultados obtidos por meio da Análise de Variância (ANOVA) e Teste de MannWhitney indicam que, no geral, não houve diferença estatisticamente significativa entre companhias familiares e não familiares ao longo dos anos e para todos os indicadores, apesar das médias apontarem que as empresas não familiares, em termos gerais, se saíram melhores. Estes resultados dialogam em certa medida com Scarpin, Almeida e Machado (2012) e Kreuzberg, Cunha e Popik (2016) pela inconclusividade dos resultados de modo geral e corroboram de algum modo com Zborowski (2009) e Politelo e Cunha (2014), Goes, Martins e Machado Filho (2017) e Bianchet et al. (2019) pela leve tendência, encontrada neste estudo, de superioridade do grupo não familiar.

Testou-se também a hipótese de que as empresas familiares em termos de posição acionária (controle ou propriedade) que detenham em sua gestão (C.A. ou Diretoria) membros familiares, poderiam restringir o conflito de interesse entre administradores/gestores e proprietários. Observando as médias em si, os resultados indicam que o grupo sem gestão familiar demonstrou desempenho superior em todos os cinco indicadores. Porém, por meio dos dados obtidos, não se pôde confirmar tal percepção uma vez que, pela ANOVA e Teste U, as médias do grupo sem gestão familiar são indiferentes em relação ao grupo com gestão familiar. Estes achados estão em discordância com o estudo de Silva et. al (2015).

Com isso, sob à luz da indiferença trazida pela ANOVA e pelo Teste de MannWhitney e pelas diferenciações apresentadas na análise descritiva e nos momentos de diferença estatisticamente relevante, constrói-se um panorama de que quanto mais família envolvida no negócio, piores são os resultados conquistados pela empresa. Isto se deve aos resultados obtidos, onde comparando dois grupos já familiares, um que tenha gestão familiar e outro não, o segundo grupo se mostrou com média superior, sugerindo que empresas familiares em termos de controle ou propriedade devem se afastar da gestão, deixando em tese nas mãos de profissionais que efetivamente tenham aptidão para o cargo e não simplesmente pelo fato destes serem consanguíneos (mesmo que tenham competência para tal).

Neste sentido, as decisões relevantes que devem ser tomadas pelos membros da família podem buscar beneficiar a família a curto prazo e ser prejudicial à companhia a longo prazo. A análise descritiva geral, entre empresas familiares e não familiares, corrobora com tal afirmação, onde as empresas não familiares apresentaram médias maiores, indicando que a eficiência dos resultados é inversamente proporcional a presença familiar. Apesar disso, as médias, no geral, se apresentaram indiferentes estatisticamente pela ANOVA e Teste de Mann-Whitney. 


\section{Análise do Desempenho Contábil-Financeiro das \\ Empresas Familiares e Não Familiares}

Como contribuição para literatura, o estudo adiciona ao utilizar indicadores de vertentes distintas e por um período amostral de longo prazo. Além disso, o trabalho se junta ao grupo de pesquisas onde existe superioridade de resultados das empresas não familiares, ou no limite, há similaridade entre os dois grupos. Como contribuição prática, esta pesquisa pode prover ao investidor sugestão de que as empresas não familiares podem gerar melhores retornos ao longo do tempo, e caso não existam resultados superiores, tais resultados, em média, serão semelhantes aos de empresas familiares.

Vale descartar, por fim, que os resultados obtidos podem ter relação com as medidas utilizadas para caracterizar uma empresa familiar. Esta pesquisa se utilizou de critérios mais amplos que as pesquisas basilares utilizaram, em geral. A ideia da escolha destes parâmetros foi delimitar estas empresas sem que existisse a possibilidade de uma empresa em termos de controle, gestão e propriedade possuir lastro familiar, mesmo que diluído pelas complexas estruturas organizacionais (ou seja, aparentar ser não familiar, mas ter características para tal), e ser considerada não familiar. É possível, contudo, que definições mais restritas ou mesmo diferentes das usadas neste estudo possam variar os resultados.

Para pesquisas futuras, recomenda-se a utilização de outras métricas para comparação entre estes dois grupos, que possam ir além da análise da governança corporativa. Sugere-se também, estudos que exaustem a definição de empresa familiar, uma vez que a definição de família delimita os grupos e fada os resultados. De maneira geral, deve-se incentivar o estudo deste nicho de pesquisa, pois a maioria das empresas iniciam como familiares, e a ingerência particular nas decisões em detrimento dos interesses de todos os stakeholders pode existir até nas empresas mais estruturalmente complexas.

\section{REFERÊNCIAS}

ALI, A.; CHEN, T-Y.; RADHAKRISHNAN, S. Corporate disclosures by family firms. Journal of Accounting and Economics, v. 44, n.1-2, p. 238-286, 2007.

AN, Y.; NAUGHTON, T. The impact of family ownership on firm value and earning quality: Evidence from Korea. Anais... European Financial Management Association Conference, Milan, Italy, p. 1-29, 2009.

ANDERSON, C.; REEB, D. M. Founding family ownership and firm performance: evidence from the S\&P 500. The Journal of Finance, v. 58, n. 3, p. 1301-1328, 2003.

ANDRADE, M. M. Como preparar trabalhos para cursos de Pós-Graduação: noções práticas. 6. ed. São Paulo: Atlas, 2004.

ASSAF NETO, A. Valuation: Métricas de Valor e avaliação de empresas. $1^{a}$ ed. São Paulo: Atlas, 2014.

BERNHOEFT, R. Empresa familiar: sucessão profissionalizada ou sobrevivência comprometida. 2 ed. São Paulo: Nobel, 1991. 
BIANCHET, T. D. S. A.; ZANIN, A.; MAZZIONI, S.; MOURA, G. D. Diferenças no valor adicionado em empresas familiares e não familiares listadas na BM\&FBovespa. Enfoque, v. 38, n. 1, p. 85, 2019.

BLOOMBERG. Bloomberg. Disponível em: <https://www.bloomberg.com.br/>. Acessado 20/07/2017.

CAMARGOS, M. A.; BARBOSA, F. D. Análise do desempenho econômico-financeiro e da criação de sinergias em processos de fusão e aquisição do mercado brasileiro ocorrido entre 1995 e 1999. Caderno de Pesquisas em Administração, v. 12, n. 2, p. 99-115,2005.

CASCINO, S.; PUGLIESE, A.; MUSSOLINO, D.; SANSONE, C. The Influence of Family Ownership on the Quality of Accounting Information. Family Business Review, v. 23, n. 3, p. 246-265, 2010.

COMITÊ DE PRONUNCIAMENTOS CONTÁBEIS. CPC 18 (R2): investimento em coligada e em empreendimento controlado em conjunto. 2012. Disponível em: < http://static.cpc.mediagroup.com.br/Documentos/263_CPC_18_(R2)_rev\%2008.pdf>. Acessado em: 05/05/2017.

GOES, T. H. M.; MARTINS, H. H.; MACHADO FILHO, C. A. P. Desempenho financeiro de empresas com características familiares: análise de empresas brasileiras listadas na BM\&F. REGE-Revista de Gestão, v. 24, n. 3, p. 197-209, 2017.

GUJARATI, D. Econometria Básica. Rio de Janeiro: Campus/Elsevier, 2006.

KREUZBERG, F; CUNHA, P. R.;POPIK, F. Relação dos Dividendos, Dívida e Conselho de Administração com o Desempenho: Um Comparativo entre Empresas Familiares e não Familiares. Revista Ambiente Contábil, v. 8, n. 1, p. 34-59, 2016.

LAKATOS, E. M.;MARCONI, M. A. Fundamentos de metodologia científica. 4. ed. São Paulo: Atlas, 2001.

LEMMON, M. L.; LINS K. V.. Ownership Structure, Corporate Governance, and Firm Value: Evidence from the East Asian Financial Crisis. The Journal of Finances, v. 53, n. 4, p. 1445-1468, 2003.

LODI, J. B. A Empresa familiar. São Paulo: Pioneira,1998.

LUNARDI, M. A.; BARBOSA, E. T.; RODRIGUES JUNIOR, M. M.; SILVA, T. P.; NAKAMURA, W. T. Criação de valor no desempenho econômico de empresas familiares e não familiares brasileiras. Revista Evidenciação Contábil \& Finanças, v. 5, n. 1, p. 94-112, 2017. 
POLITELO. L.; CUNHA, P. R. Estrutura de propriedade como dimensão da governança corporativa e sua relação com o desempenho das empresas familiares. Anais... Congresso USP de Contabilidade e Controladoria, São Paulo, USP, 2014.

PROCIANOY, J. L.; CASELANY, C. N. (Emissão de ações como fonte de crescimento ou como fonte de redução do risco financeiro: resultados empíricos. Revista de Administração, v. 32, n. 3, p. 70-81, 1997.

SANTOS, T. R.; SILVA, J. O. A influência da família tem algum efeito? Análise da remuneração dos executivos das empresas familiares e não familiares. Revista de Contabilidade e Organizações, v. 12, p. e148149-e148149, 2018.

SCARPIN, J. E.; ALMEIDA, D. M.; MACHADO, D. G. Endividamento e Lucratividade: Um Estudo em Empresas Familiares e não Familiares que compõem o Índice Ibrx-100 da Bm\&Fbovespa. Revista Ambiente Contábil, v. 4, n. 2, p. 93-109, 2012.

SCHULZE, W. S.; LUBATKIN, M. H.; DINO, R. N.; BUCHHOLTZ, A. K. Agency relationships in family firms: theory and evidence. Organization Science, v. 12, n. 2, p. 99$116,2001$.

SETIA-ATMAJA, L. Y.;TANEWSKI, G.; SKULLY, M. T. The role of dividends, debt and board structure in the governance of Family controlled firms. Journal of Business Finance and Accounting, v. 36, n. 7, p. 863-898, 2009

SILVA, G. E.; OLIVEIRA, G. J.; MACEDO, M. A. S.; MARQUES, J. A. V. C. Análise do Impacto do Controle Familiar Sobre a Qualidade das Informações Contábeis no Brasil: um Estudo com Foco na Análise de Relevância do Lucro. Revista de Finanças Aplicadas, v. 4, p. 1-30, 2015.

SOARES, E. Metodologia Científica: Lógica, epistemologia e normas. São Paulo: Atlas, 2003.

STEVENSON, W. J. Estatística aplicada à administração. 1 ed, São Paulo: Harbra, 2001.

UPTON, N.; TEAL, E. J.; FELAN, J. T. Strategic and business planning practices of fast growth family firms. Journal of Small Business Management, v. 39, n. 1, p. 60-72, 2001.

VILLALONGA, B.;R. AMIT. How Do Family Ownership, Control, and Management, Affect Firm Value? Journal of Financial Economics, v. 80, n. 2, p. 385-417, 2006.

WANG, D. Founding family ownership and earnings quality. Journal of Accounting Research, v. 44, n. 3, p. 619-656, 2006.

ZBOROWSKI, I. B. Empresas Familiares no Índice Bovespa. 67 fl. Dissertação (Mestrado em Administração) - Universidade Federal do Rio de Janeiro - UFRJ, Instituto COPPEAD de Administração, 2009. 